\title{
Cognitive and balance impairments in people with incidental white matter hyperintensities
}

\author{
Amr El Sayed Ali Mohamed Tag Eldin, Wafik Said Bahnasy *iD, Naglaa Lotfy Dabees and \\ Hazem Abd El-Rahman Fayed
}

\begin{abstract}
Background: White matter hyperintensities (WMHs) is the most frequent type of cerebral small vessel diseases and a common incidental finding in MRI films of the geriatric population. The objectives of this work were to study the existence of occult cognitive and balance impairments in subjects with accidentally discovered WMHs.

Methods: The study was conducted on 44 subjects with accidentally discovered WMHs and 24 non-WMHs subjects submitted to the advanced activity of daily living scale (AADLs), a neurocognitive battery assessing different cognitive domains, Berg balance test (BBT), computerized dynamic posturography (CDP), and brain MRI diffusion tensor tractography (DTT).

Results: WMHs subjects showed a significant decrease in AADLs as well as visual and vestibular ratios of CDP. Regarding the neurocognitive battery, there were significant decreases in MoCA as well as arithmetic test and block design of Wechsler adult intelligence scale-IV in WMHs compared to non-WMHs subjects' groups ( $p$ value $<0.001$ ). Concerning Wisconsin Card Sorting subtests, each preservative response, preservative errors, non-preservative errors and trials to complete the 1st category showed a highly significant increase in WMHs compared to non-WMHs subjects ( $p$ values $<0.001$ ). DTT showed a substantial reduction in fractional anisotropy (FA) of each corticospinal tract, thalamocortical connectivity, and arcuate fasciculi.
\end{abstract}

Conclusion: Subjects with WMHs have lower cognitive performance and subtle balance impairment which greatly impair their ADLs.

Keywords: White matter hyperintensities, Posturography, Cognitive impairment, DTT

\section{Introduction}

White matter hyperintensities (WMHs) of presumed vascular origin are defined as areas of aberrant white matter appearance with increased intensity in T2WI and FLAIR images away from areas of cortical lesions or ventricular enlargement and not related to demyelinating disease, leukodystrophy or other nonvascular causes [1]. WMHs is the most frequent type of cerebral small vessel diseases (CSVDs) while advanced age seems to be the

\footnotetext{
* Correspondence: wafiq.elbahnasi@med.tanta.edu.eg

The Departments of Neuropsychiatry, and Diagnostic Radiology, Tanta University Hospitals, Faculty of Medicine, Tanta University, zip code 31527 Tanta, Egypt
}

\section{Springer Open}

most important risk factor. The incidence of accidentally discovered WMHs is very low before the age of 55, and they could be identified in about $25 \%$ of MRI images for those $>60$ years, and $90 \%$ of asymptomatic subjects $>70$ years [2]. WMHs seem to have multifactorial etiologies including endothelial dysfunction, inflammation, increased vascular permeability, BBB disruption, and venous insufficiency [3].

Most MRI reporters consider WMHs as a normal agerelated finding, but there is a paucity of information about their clinical significance and the permissible spectrum of their benign range [4]. Meticulous assessment of asymptomatic WMHs subjects reveals their (c) The Author(s). 2020 Open Access This article is licensed under a Creative Commons Attribution 4.0 International License, which permits use, sharing, adaptation, distribution and reproduction in any medium or format, as long as you give appropriate credit to the original author(s) and the source, provide a link to the Creative Commons licence, and indicate if changes were made. The images or other third party material in this article are included in the article's Creative Commons licence, unless indicated otherwise in a credit line to the material. If material is not included in the article's Creative Commons licence and your intended use is not permitted by statutory regulation or exceeds the permitted use, you will need to obtain permission directly from the copyright holder. To view a copy of this licence, visit http://creativecommons.org/licenses/by/4.0/. 
suffering of subtler cognitive, gait, balance, and psychiatric disturbances. At the same time, individuals with extensive WMHs are at a double risk of dementia (vascular or mixed types) and/or triple risk of cerebrovascular strokes (occlusive or hemorrhagic) [5].

\section{Aim of the work}

The aim was to study the existence and pattern of cognitive as well as balance impairments in patients with occult WMHs of presumed vascular origin.

\section{Methods}

This work was an observational randomized crosssectional study conducted on an initial sample of 162 young-old subjects aged 60-69 years [6] who underwent brain MRI due to various causes in the period from the 1st of December 2018 till the end of December 2019. The flowchart of studied subjects is shown in Fig. 1 where 75 were uninvolved due to the presence of one or more exclusion criteria, 19 subjects refused enrollment in the study and the remaining 68 ones were divided to 2 groups regarding the presence or absence of WMHs; group 1 included 44 subjects with accidentally discovered WMHs of presumed vascular origin and group II consisted of 24 subjects with no WMHs in their MRI films (patients with unilateral or bilateral periventricular caps were included in this group).

Exclusion criteria encompassed patients with a history of clinically evident stroke, cognitive impairment, manifest orthopedic problems, cerebral autosomal dominant/ recessive arteriopathy with subcortical infarcts and leukoencephalopathy (CADASIL / CARASIL), preexisting psychiatric or cognitive disorders as well as those with MRI contraindications, chronic vertiginous problems, and chronic medical problems or use of medications affecting cognition and/or balance.

The study protocol was approved by the Research Ethics Committee and Quality Assurance Unit (approval code: $32762 / 12 / 18$ ), participants were voluntary and informed consent was obtained before engagement in the study.

Brain MRI images were performed for diagnosis and grading of WMHs used the age-related white matter changes (ARWMC) visual rating scale [7]. Diffusion tensor tractography (DTT) and 3D microstructural orientation of the corticospinal tract (CST), thalamocortical connectivity (TCC) as well as inferior longitudinal and arcuate fasciculi [8]. MRI was acquired using 1.5-Tesla, General Electric Scanner with quadrature 8 channels head coil, GE Healthcare, Milwaukee, WI, USA. (Additional file 1)

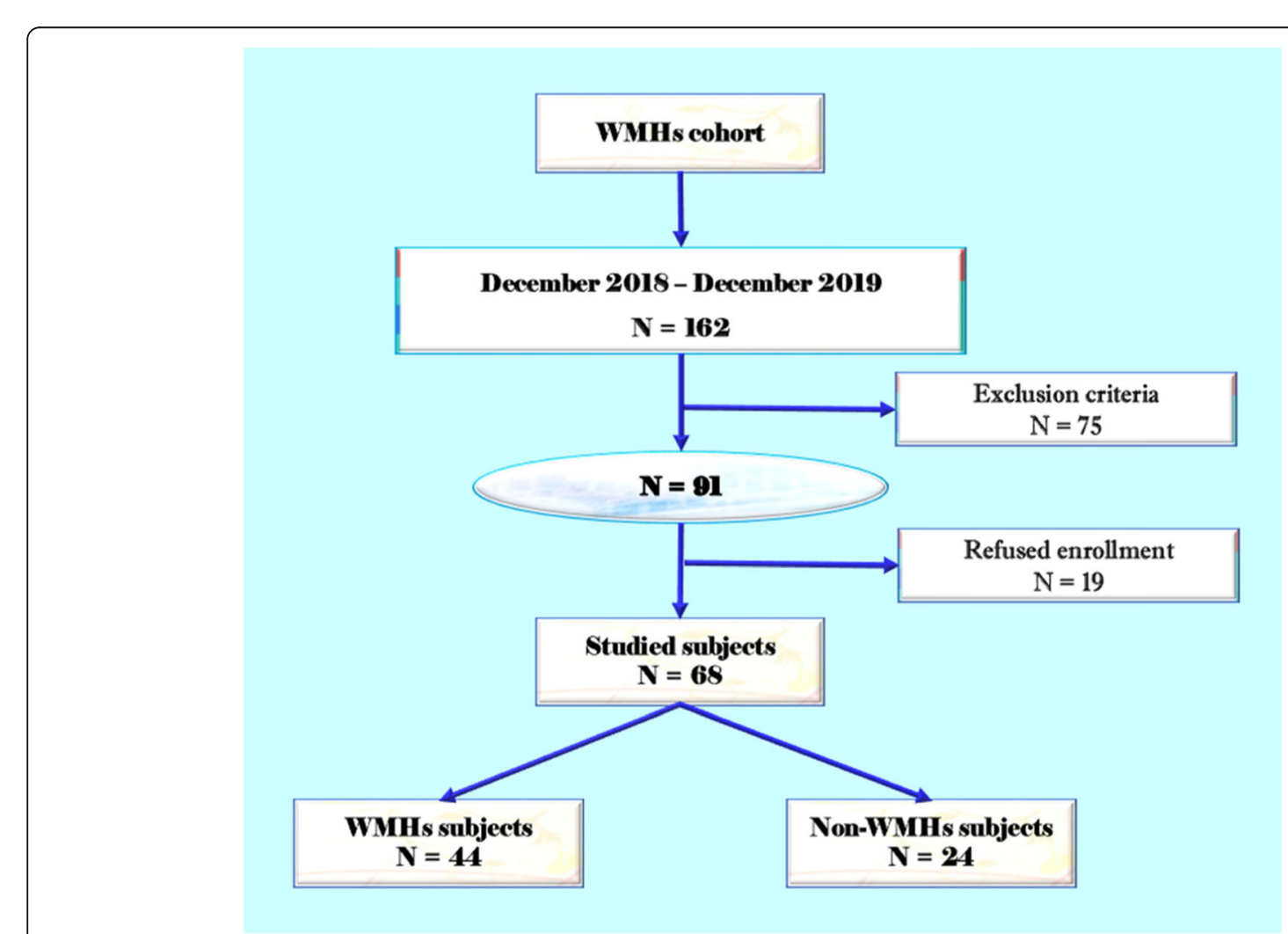

Fig. 1 Flowchart of studied subjects 
Studied individuals were subjected to history taking, neurological examination, the Montgomery-Åsberg Depression Rating Scale (MADRS), and the advanced activities of daily living scale (AADLs) [9], as well as a battery of neurocognitive tests, included the Montreal Cognitive Assessment Scale (MoCA) Arabic Version [10], trailmaking test, [11] subtest of Wechsler Adult Intelligence Scale-IV (WAIS-IV), [12] Stroop Color-Word Test [13] and Wisconsin Card Sorting Test [14] (WCST) (computerized version) derived from the Psychology Experiment Building Language (PEBL).

Balance assessment was done using the Berg Balance Test (BBT) [15] as well as the computerized dynamic posturography (CDP), sensory organization test (SOT) was also performed to examine the somatosensory (SOM), visual (VIS), and vestibular (VEST) balance systems using the Balance Quest provided by Framiral, Cannes, France (Multitest Equilibre 6.1.37.0) with static/dynamic platform by Micromedical Technologies (http://perso.wanadoo.fr/ framiral/multi_gb.htm) [16] (Additional file 2).

Statistical analysis was conducted using SPSS Prism, version 20, 2013 created by IBM, Chicago, IL, USA. Statistical differences were tested using chi-square for categorical variables and Student's $t$ test for numerical ones. For bilaterally assessed parameters, all included subjects were represented by the mean measure of both sides. Correlation analysis was performed using Pearson's correlation test. $P$ value $<0.05$ was considered statistically significant.

\section{Results}

The study included 44 subjects with accidentally discovered WMHs aged 64.61 \pm 3.85, 26 (59.1\%) were males and their ARWMC score was $11.89 \pm 4.16$ points (Table 1 ).

The main indications of brain MRI were 13/44 (29.5\%) dizziness, 9 (20.5\%) headache, 8 (18.2\%) tinnitus, 6 (13.6\%) subjective cognitive decline, 5 (11.4\%) somatoform disorder, and 3 (6.8\%) facial numbness. Both WMHs and non-WMHs groups showed non-significant

Table 1 Demographic data and vascular risks among WMHs (group I) and non-WMHs subjects (group II)

\begin{tabular}{llll}
\hline & Group I $(\boldsymbol{n}=\mathbf{4 4})$ & Group II $(\boldsymbol{n}=\mathbf{2 4})$ & $\boldsymbol{p}$ value \\
\hline Age & $64.61 \pm 3.85$ & $62.02 \pm 3.70$ & 0.216 \\
Sex $(\mathrm{male} \%)$ & $26(59.1 \%)$ & $14(58.3 \%)$ & 0.952 \\
BMI $\left(\mathrm{kg} / \mathrm{m}^{2}\right)$ & $36.2 \pm 3.6$ & $34.9 \pm 4.3$ & 0.189 \\
Hypertension (\%) & $28(63.6 \%)$ & $8(33.3 \%)$ & $0.017^{*}$ \\
Diabetes (\%) & $14(31.8 \%)$ & $8(33.3 \%)$ & 0.898 \\
Smokers (\%) & $18(40.9 \%)$ & $6(25 \%)$ & 0.190 \\
IHD (\%) & $9(20.5 \%)$ & $5(20.8 \%)$ & 0.971 \\
Arrhythmia (\%) & $7(15.9 \%)$ & $3(12.5 \%)$ & 0.704 \\
\hline
\end{tabular}

*Significant differences regarding the self-reported indications of brain imaging (Table 2).

Regarding vascular risks, the results showed a significant increase in the incidence of hypertension among WMHs subjects compared to non-WMH ones ( $p$ value $=0.017)$. Other modifiable and non-modifiable common vascular risks including subjects' age and sex as well as body mass index, diabetes, dyslipidemia, smoking, arrhythmias, and ischemic heart disease showed nonsignificant differences between both studied groups with $p$ value $>0.05$ (Table 1$)$.

The results of the present study revealed significant decreases in AADLs as well as MoCA scales in WMHs subjects compared to the non-WMHs group with $p$ values $<0.001$ and 0.034 , respectively. At the same time, the WMHs group showed significant increases in each of MADRS, trail-making test, and Stroop color-word test with $p$ values $<0.001$. Regarding the WAIS-IV subtest, there were significant decreases in each arithmetic test and block design in WMHs compared to non-WMHs subjects' groups ( $p$ value $<0.001)$ while digit span forwards and backward as well as language vocabulary showed non-significant differences. Concerning WCST subtests, each preservative response, preservative errors, non-preservative errors, and trials to complete 1st category showed a highly significant increase while conceptual level response and the number of categories showed significant decreases in WMHs compared to nonWMHs ( $p$ values $<0.001)$ (Table 3 ).

The study showed a non-significant difference between both studied groups regarding BBT while CDP revealed significant decreases of VIS and VEST ratios in the WMHs group compared to non-WMHs one with $p$ values $<0.001$. On the other hand, the SOM ratio showed a non-significant difference between both studied groups ( $p$ value $=0.129)$ (Tables 3 and 4, Fig. 2).

In respect to MRI results, the ARWMC score was $11.89 \pm 4.16$ points for the WMHs group which showed a significant increase in occult lacunar brain infarcts (LBIs) number compared to non-WMHs subjects. Regarding the DTT data, the results revealed highly

Table 2 Comparison between WMHs and non-WMHs groups regarding the indications of brain $\mathrm{MRI}$

\begin{tabular}{llllll}
\hline & $\begin{array}{l}\text { WMHs } \\
\text { (n: 44) }\end{array}$ & $\begin{array}{l}\text { Non- } \\
\text { WMHs } \\
\text { (n: 24) }\end{array}$ & \multicolumn{2}{l}{ Chi-square } \\
\cline { 5 - 6 } Dizziness & $13(29.5 \%)$ & $2(8.3 \%)$ & 4.062 & 0.044 \\
Headache & $9(20.5 \%)$ & $6(25 \%)$ & 0.187 & 0.666 \\
Tinnitus & $8(18.2 \%)$ & $2(8.3 \%)$ & 1.201 & 0.273 \\
Subjective cognitive decline & $6(13.6 \%)$ & $6(25 \%)$ & 1.379 & 0.240 \\
Somatoform disorder & $5(11.4 \%)$ & $6(25 \%)$ & 2.132 & 0.144 \\
Facial numbness & $3(6.8 \%)$ & $2(8.3 \%)$ & 0.049 & 0.819 \\
\hline
\end{tabular}


Table 3 Comparison between the WMHs (group I) and non-WMHs subjects (group II) regarding studied scales

\begin{tabular}{|c|c|c|c|c|}
\hline & \multirow[t]{2}{*}{ Group I } & \multirow[t]{2}{*}{ Group II } & \multicolumn{2}{|l|}{$t$ test } \\
\hline & & & $t$ value & $p$ value \\
\hline AADLS & $24.57 \pm 4.25$ & $28.70 \pm 3.35$ & 4.042 & $<0.001^{*}$ \\
\hline MADRS & $18.11 \pm 8.76$ & $10.39 \pm 5.11$ & 3.888 & $<0.001^{*}$ \\
\hline Berg balance test & $45.09 \pm 2.25$ & $44.75 \pm 2.15$ & 0.606 & 0.546 \\
\hline MoCA & $24.77 \pm 1.44$ & $25.50 \pm 1.06$ & 2.164 & $0.034^{*}$ \\
\hline Trail-making test & $295.32 \pm 48.54$ & $255.96 \pm 23.66$ & 3.729 & $<0.001^{*}$ \\
\hline Stroop color word test & $171.32 \pm 15.22$ & $122.00 \pm 23.24$ & 10.554 & $<0.001^{*}$ \\
\hline \multicolumn{5}{|c|}{ Wechsler Adult Intelligence Scale IV } \\
\hline Digit span forward & $4.91 \pm 0.86$ & $5.25 \pm 0.94$ & 1.512 & 0.135 \\
\hline Digit span backwards & $4.30 \pm 0.76$ & $4.50 \pm 0.66$ & 1.104 & 0.273 \\
\hline Arithmetic test & $7.86 \pm 1.17$ & $10.83 \pm 1.71$ & 8.453 & $<0.001^{*}$ \\
\hline Language vocabulary & $22.64 \pm 2.63$ & $22.79 \pm 1.53$ & 0.265 & 0.792 \\
\hline Block design & $9.43 \pm 1.42$ & $12.96 \pm 1.33$ & 9.989 & $<0.001^{*}$ \\
\hline \multicolumn{5}{|l|}{$\underline{\text { Wisconsin Card Sorting Test }}$} \\
\hline Preservative response & $28.57 \pm 3.53$ & $23.29 \pm 4.05$ & 5.594 & $<0.001^{*}$ \\
\hline Preservative errors & $16.91 \pm 3.64$ & $11.63 \pm 2.20$ & 6.481 & $<0.001^{*}$ \\
\hline Non-preservative errors & $17.23 \pm 2.40$ & $8.79 \pm 1.47$ & 15.653 & $<0.001^{*}$ \\
\hline Trials to complete 1 st category & $13.18 \pm 1.56$ & $11.54 \pm 1.02$ & 4.632 & $<0.001^{*}$ \\
\hline Conceptual level response & $33.11 \pm 4.72$ & $41.83 \pm 2.87$ & 8.247 & $<0.001^{*}$ \\
\hline No. of categories & $2.70 \pm 0.73$ & $4.33 \pm 0.82$ & 8.405 & $<0.001^{*}$ \\
\hline
\end{tabular}

AADLs advanced activities of daily living scale, MADRS Montgomery-Åsberg Depression Rating Scale, MoCA Montreal cognitive assessment scale *Significant

Table 4 Comparison between the WMHs (group I) and non-WMHs subjects (group II) regarding the assessed investigations

\begin{tabular}{|c|c|c|c|c|}
\hline & \multirow[t]{2}{*}{ Group I } & \multirow[t]{2}{*}{ Group II } & \multicolumn{2}{|l|}{$t$ test } \\
\hline & & & $t$ value & $p$ value \\
\hline ARWMC & $11.89 \pm 4.16$ & $1.79 \pm 1.18$ & 11.599 & $0.001^{*}$ \\
\hline Occult LBls & $1.36 \pm 0.84$ & $0.46 \pm 0.59$ & 4.693 & $0.001^{*}$ \\
\hline CDP-SOM ratio & $93.18 \pm 13.76$ & $97.54 \pm 2.00$ & 1.539 & 0.129 \\
\hline CDP-VIS ratio & $78.20 \pm 3.26$ & $89.17 \pm 2.43$ & 14.418 & $0.001^{*}$ \\
\hline CDP-VEST ratio & $49.09 \pm 3.64$ & $67.54 \pm 3.01$ & 21.183 & $0.001^{*}$ \\
\hline Corticospinal tract (mean FA) & $0.58 \pm 0.06$ & $0.72 \pm 0.07$ & 8.321 & $0.001^{*}$ \\
\hline Corticospinal tract (density) & $373.00 \pm 24.11$ & $358.08 \pm 25.90$ & 2.375 & $0.020^{*}$ \\
\hline TCT (mean FA) & $0.46 \pm 0.06$ & $0.70 \pm 0.07$ & 14.203 & $0.001^{*}$ \\
\hline TCC (density) & $662.39 \pm 75.36$ & $674.04 \pm 74.58$ & 0.612 & 0.543 \\
\hline Arcute faciculus (mean FA) & $0.36 \pm 0.06$ & $0.47 \pm 0.02$ & 8.943 & $0.001^{*}$ \\
\hline Arcute faciculus (density) & $237.14 \pm 24.04$ & $230.33 \pm 24.59$ & 1.106 & 0.273 \\
\hline ILF (mean FA) & $0.42 \pm 0.03$ & $0.42 \pm 0.03$ & 0.407 & 0.686 \\
\hline ILF (density) & $228.45 \pm 15.85$ & $226.58 \pm 15.37$ & 0.470 & 0.640 \\
\hline
\end{tabular}

ARWMC age-related white matter changes scale, CDP-SOM, VIS, VEST computerized dynamic posturography somatosensory, visual, and vestibular, FA fractional anisotropy, MCP middle cerebellar peduncle, MCT mean cortical thickness, TCC thalamo-cortical connectivity *Significant 


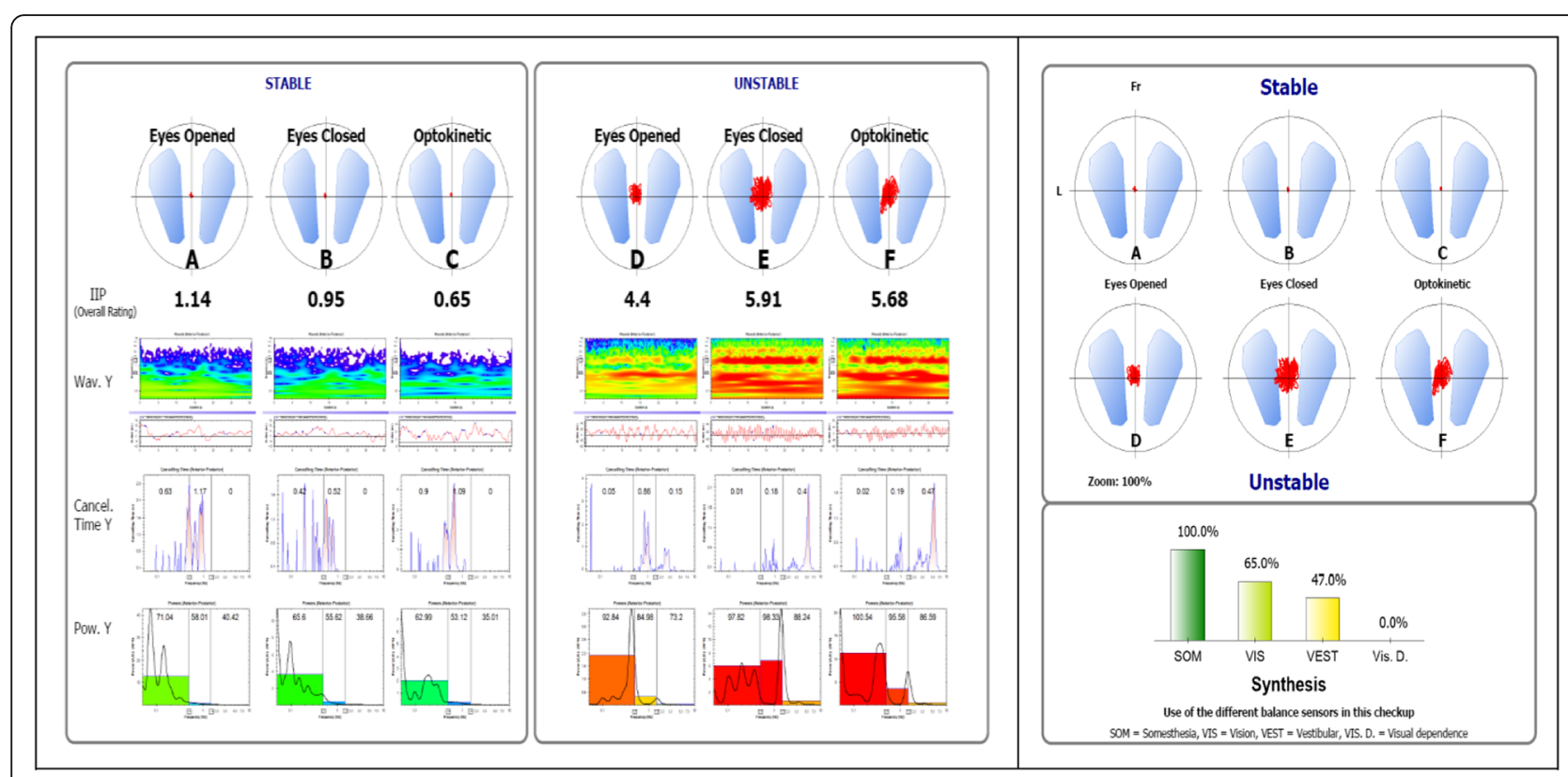

Fig. 2 Computerized dynamic posturography sensory analysis ratios of a WMHs subject showing impaired visual and vestibular inputs with normal somatosensory balance systems

significant reductions in mean FA for CST, TCC, and arcuate fasciculus in WMHs compared to non-WMHs groups while inferior longitudinal fasciculus FA showed non-significant differences. At the same time, all studied tracts densities showed non-significant differences between both studied groups (Table 4, Fig. 3).

Correlation data analysis revealed negative correlations between the ARWMC score and each of AADLs and MoCA, as well as VIS/VEST ratios and CST FA with $p$ values $<0.001$. At the same time, ARMWC showed a positive correlation with patients' age and MADRS (Fig. 4).

\section{Discussion}

The present study revealed that hypertension is the major vascular risk of WMHs while other common vascular risk factors including diabetes, dyslipidemia, obesity, smoking, and heart disease showed non-significant relation with WMHs severity. At the same time, the results did not identify the effect of advanced age on WMHs progression possibly due to the selection criteria of a specific age (young-old geriatric subjects). These results are agreeing with Croall and colleagues, 2018 [17] as well as Wardlaw and colleagues, 2019 [3] who stated that hypertension is a major risk of WMHs, yet the disorder is highly heterogenous and multi-etiological where heritable factors play a major role in its pathogenesis. On the other hand, Yu and colleagues, 2018 [18] as well as Walsh and colleagues, 2019 [19] found significant associations between the existence of type $2 \mathrm{DM}$ as well as obesity and WMHs progression possibly due to inclusion of patients with metabolic syndrome and clinically evident strokes rather than subjects with accidentally discovered asymptomatic WMHs.

The results of this work identified lower cognitive performance, more depressive symptoms (feeling of sadness, helplessness, and hopelessness) as well as reduced activity of daily livings (ADLs) in WMHs subjects. These data are going with the study of Madden and colleagues, 2017 [20] who hypothesized that WMHs are neither silent nor innocent but brain resilience may delay their clinical implications by undergoing several neuromodulatory processes including reduction in the cost of wiring, reorganization of the resting-state and default mode networks as well as paradoxical functional hyperconnectivity.

The study showed that the MoCA scale at 26 points had $58 \%$ sensitivity and $70 \%$ specificity for the diagnosis of cognitive impairments associating WMHs (Fig. 5). This low sensitivity and specificity indicate that the MoCA scale is not suitable for the evaluation of the subtler cognitive impairments associating with WMHs (Fig. 4). This result is parallel with that of Abd Ghafar and colleagues, 2019 [21] who declared that global cognitive assessment scales including MoCA could be a sensitive screening test for patients with vascular cognitive impairment yet this sensitivity is much lowered in preclinical cases with subjective cognitive decline including occult WMHs subjects.

Neurocognitive assessment of WMHs subjects revealed marked affection of attention and executive functions while language vocabulary and memory were little impaired. These results are in harmony with that of Rensma and colleagues, 2018 [22] as well as Bahnasy 


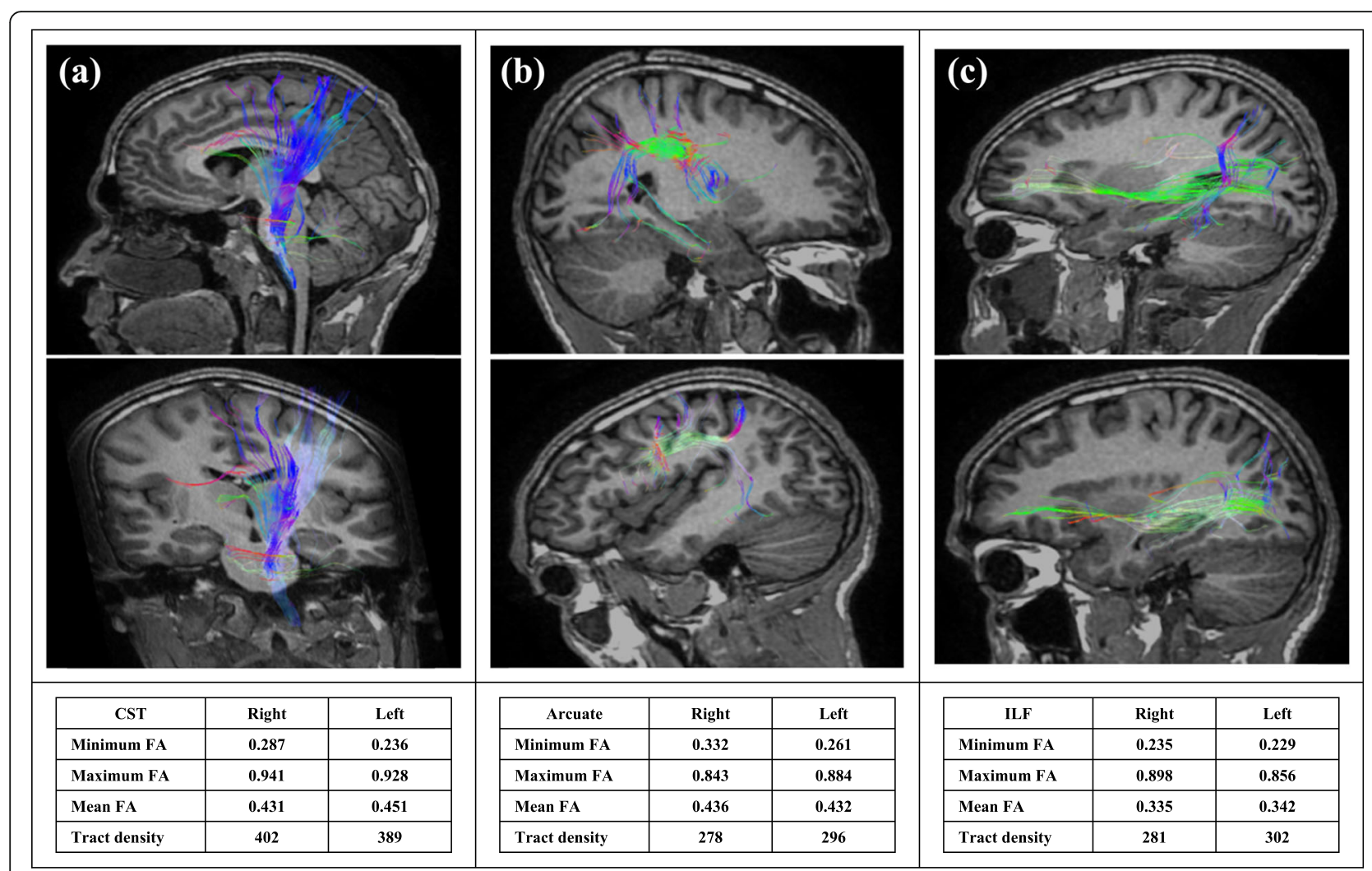

Fig. 3 Diffusion tensor tractography of an included WMHs subject a corticospinal, b arcuate fasciculus, $\mathbf{c}$ inferior longitudinal fasciculus

and colleagues, 2018 [23] who concluded that subjects with extensive WMHs showed subnormal executive functions (information processing speed, set shift, and multitasking) and reduced capacity for sustained attention with relative sparing of episodic memory and delayed recall. On the other hand, they identified significant language dysfunctions in their studied subjects which is not compatible with our results possibly due to different study design and inclusion of clinically symptomatic stroke and mild cognitive impairment patients.
The results of the present study showed nonsignificant differences between WMHs and non-WMHs subjects regarding the BBT which is in harmony with the work of Shen and colleagues, 2016 [24] who concluded that BBT is an insensitive biomarker for increased risks of falls in subjects with WMHs.

The results of the present work showed impaired static and dynamic balance control in WMHs subjects evidenced by decreased VIS and VEST ratios which were negatively correlated with WMHs disease burden. These

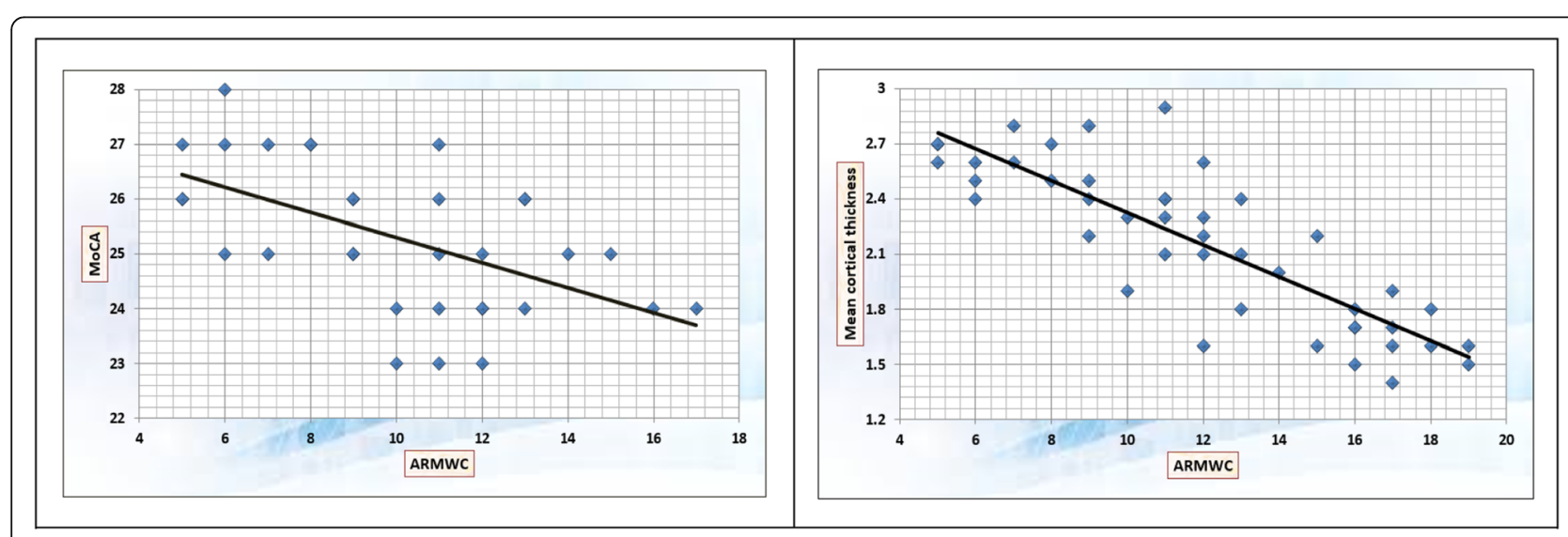

Fig. 4 A negative correlation between the ARMWC scale and each of MoCA scale (left) and mean cortical thickness (right) 


\section{ROC Curve}

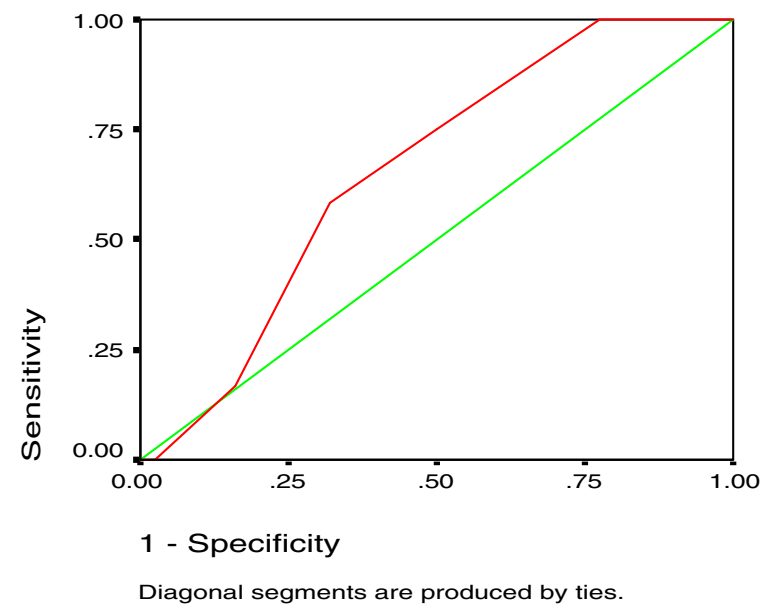

\begin{tabular}{|c|c|c|c|c|c|c|c|}
\hline \multirow{2}{*}{ MoCA } & Cutoff & AUC & Sensitivity & Specificity & PPV & NPV & Accuracy \\
\cline { 2 - 8 } & $\mathbf{2 6}$ & $\mathbf{0 . 6 5 8}$ & $\mathbf{5 8}$ & $\mathbf{7 0}$ & $\mathbf{5 0}$ & $\mathbf{7 5}$ & $\mathbf{6 5}$ \\
\hline
\end{tabular}

Fig. 5 ROC curve analysis for MoCA sensitivity and specificity in WMHs subjects

results are in harmony with that of Shen and colleagues, 2016 [24] as well as Moscufo and colleagues, 2018 [25] who concluded that WMHs are at increased risk of falls due to associated balance and gait dysfunctions. They attributed these mobility impairments to the subtle white matter microstructural abnormalities, particularly in the corpus callosum.

The study revealed reduction of FA in each of CST, TCC, and arcuate fasciculi of WMHs subjects with preserved tracts, densities pointing to the microstructural connectivity changes induced by WMHs. At the same time, there was an observable increased heterogenicity of axon FA (myelination) in the studied tracts denoting decreased synchrony of impulses transduction. These results are passing with that of Loos and colleagues, 2018 [26] as well as Tuladhar and colleague, 2016 [27] who stated that WMHs is a dynamic whole-brain disorder resulting in disruption of the axons not only in the WMHs lesions but also in their normally appearing white matter penumbra. The net results are dying back of the neuronal cell bodies and disruption of brain network integrity progressing to disconnection syndrome.

A potentially important observation is the little affection of the inferior longitudinal fasciculi than other studied white matter tracts which signifies that brain areas have different susceptibilities to WMHs induced changes. These data may open a small window in a better understanding of the pathogenesis of WMHs with the consecutive introduction of more specific treating agents. These results are following the work of Frey and colleagues, 2019 [28] as well as Vangberg and colleagues, 2019 [29] who identified that certain brain regions particularly those with the aberrant structure are more vulnerable to the microstructural compromise induced by WMHs lesions possibly due to different vulnerability to the induced ischemia and neuroinflammation.

\section{Conclusion}

Subjects with WMHs have lower cognitive performance and at higher risk of falls due to balance impairments which greatly impair their ADLs. The routine MoCA and Berg balance tests are not sensitive for identification of the subtler cognitive and balance dysfunctions due to WMHs while the construction of more specific, easily applicable scales becomes an opportunity for better diagnosis and follow-up.

\section{Recommendations}

Further studies are needed to identify the impact of WMHs on brain network integrity, their clinical significance as a stroke or dementia risk as well as the permissible spectrum of their benign range in physiological aging. These points will be studied in the second phase of the study which will be a longitudinal one.

\section{Limitations}

Rating of WMHs used the ARWMC visual rating scale while automated volumetric quantification with its integrated correlation with the specific brain areas will allow 
a better insight into the strategic tracts involved in the cognitive and balance functions. At the same time, there is no consensus regarding the chronological and biological aging biomarkers related to WMHs allowing for the division of the studied subjects into physiological and pathological WMHs groups.

\section{Supplementary information}

Supplementary information accompanies this paper at https://doi.org/10. 1186/s41983-020-00228-6.

Additional file 1:. Brain MRI evaluated parameters

Additional file 2:. Berg balance and posturography

\section{Abbreviations}

AADLs: Advanced activities of daily living scale; ADLs: Activity of daily livings; ARWMC: Age-related white matter changes; CDP: Computerized dynamic posturography; CST: Corticospinal tract; CSVDs: Cerebral small vessel diseases; DTI: Diffusion tensor imaging; DTT: Diffusion tensor tractography: FA: Fractional anisotropy; MADRS: Montgomery-Åsberg Depression Rating Scale; MoCA: Montreal Cognitive Assessment Scale; SOM: Somatosensory; TCC: Thalamo-cortical connectivity; VEST: Vestibular; VIS: Visual; WAIS: Wechsler Adult Intelligence Scale; WCST: Wisconsin Card Sorting Test; WMHs: White matter hyperintensities

\section{Acknowledgements}

We would like to thank the neuropsychiatry, audiology, and diagnostic radiology medical and para-medical staff, Tanta University Hospitals, for their great help in patients' selection and neurocognitive evaluation. We also would like to thank Dr. Kareem Mohammed Ramadan: Lecturer of Diagnostic Radiology, Faculty of Medicine, Tanta University for his help in DTI acquisition.

\section{Authors' contributions}

AEAMT participated in the study's design, patients' selection, statistical analysis, data analysis, references collection, and manuscript writing, WSB participated in the study's idea, design, patients' selection, neurological examination, posturography assessment, statistical analysis, data analysis, references collection, manuscript writing, revision, and final approval, NLD participated in study's design, patients' assessment, DTT performance, manuscript revision, and final approval. HAF participated in study's idea and design, patients' assessment and inclusion, data analysis, statistical analysis, references collection, manuscript revision, and final approval. All authors have read and approved the manuscript.

\section{Funding}

No funding had been received.

\section{Availability of data and materials}

The datasets used and/or analyzed during the current study are available from the corresponding author on reasonable request.

\section{Ethics approval and consent to participate}

The manuscript was approved from The Research Ethics Committee and Quality Assurance Unit, Faculty of Medicine, Tanta University.

The URL: http://tqac.tanta.edu.eg/new-tqac/

QualityAssuranceUnit@hotmail.com

-Approval Code: 32762/12/18

-Name of the PI: Amr ElSayed Tag Eldin.

-Name of the department: Neuropsychiatry.

-Type of the research: MSC

-Date of approval: December 2018.

-The study's protocol had permitted by The Research Ethics Committee and Quality Assurance Unit, Faculty of Medicine, Tanta University. Participations were voluntary, and informed consents were approved by all participants and any possible risks were clarified.

\section{Consent of publication}

Not applicable.

\section{Competing interests}

All authors disclose that they have no competing interests related to the study.

Received: 13 May 2020 Accepted: 21 September 2020

Published online: 29 September 2020

\section{References}

1. Ten Kate $\mathbf{M}$, Sudre $\mathrm{CH}$, den Braber A, Konijnenberg E, Nivard MG, Cardoso $\mathrm{MJ}$, et al. White matter hyperintensities and vascular risk factors in monozygotic twins. Neurobiol Aging. 2018. https://doi.org/10.1016/j. neurobiolaging.2018.02.002.

2. Cuadrado-Godia E, Dwivedi P, Sharma S, Santiago AO, Gonzalez JR, Balcells $M$, et al. Cerebral small vessel disease: A review focusing on pathophysiology, biomarkers, and machine learning strategies. J Stroke. 2018:20(3):302-20. https://doi.org/10.5853/jos.2017.02922.

3. Wardlaw JM, Smith C, Dichgans M. Small vessel disease: Mechanisms and clinical implications. Lancet Neurol. 2019;18(7):684-96. https://doi.org/10. 1016/S1474-4422(19)30079-1.

4. Rizvi B, Narkhede A, Last BS, Budge M, Tosto G, Manly JJ, et al. The effect of white matter hyperintensities on cognition is mediated by cortical atrophy. Neurobiol Aging. 2018. https://doi.org/10.1016/j.neurobiolaging.2017.12.006.

5. Langen CD, Cremers LGM, de Groot M, White T, Ikram MA, Niessen WJ, et al. Disconnection due to white matter hyperintensities is associated with lower cognitive scores. Neurolmage. 2018;183:745-56. https://doi.org/10.1016/j. neuroimage.2018.08.037.

6. Forman DE, Berman AD, McCabe CH, Baim DS, Wei JY. PTCA in the elderly: The "young-old" versus the "old-old". J Am Geriatr Soc. 1992;40(1):19-22. https://doi.org/10.1111/j.1532-5415.1992.tb01823.

7. Wahlund LO, Barkhof F, Fazekas F, Bronge L, Augustin M, Sjögren M, et al. A New Rating Scale for Age-Related White Matter Changes Applicable to MRI and CT. Stroke. 2001;32:1318-22.

8. Chung HW, Chou MC, Chen CY. Principles and limitations of computational algorithms in clinical diffusion tensor MR tractography. Am J Neuroradiol. 2011;32(1):3-13. https://doi.org/10.3174/ajnr.A2041.

9. Dias EN, da Silva JV, Pais-Ribeiro JL, Martins T. Validation of the advanced activities of daily living scale. Geriatr Nurs. 2019;40:7-12. https://doi.org/10. 1016/j.gerinurse.2018.05.008.

10. Abdel Rahman TT, El Gaafary MM. Montreal Cognitive Assessment Arabic version: Reliability and validity prevalence of mild cognitive impairment among elderly attending geriatric clubs in Cairo. Geriatr Gerontol Int. 2009;9: 54-61. https://doi.org/10.1111/j.1447-0594.2008.00509.x.

11. Cavaco S, Gonçalves A, Pinto C, Almeida E, Gomes F, Moreira I, et al. Trail Making Test: Regression-based Norms for the Portuguese Population. Arch Clin Neuropsychol. 2013;28:189-98. https://doi.org/10.1093/arclin/acs115.

12. Wechsler D. Wechsler Adult Intelligence Scale_Fourth Edition. San Antonio, TX: Pearson; 2008

13. Scarpina F, Tagini S. The Stroop Color and Word Test. Front Psychol. 2017;8: 557. https://doi.org/10.3389/fpsyg.2017.00557.

14. Eling P, Derckx K, Maes R. On the historical and conceptual background of the Wisconsin Card Sorting Test. Brain Cogn. 2008;67:247-53. https://doi. org/10.1016/j.bandc.2008.01.006.

15. Berg K, Wood-Dauphinee S, Williams JI, Maki B. Measuring balance in the elderly: validation of an instrument. Can J Pub Health. 1992;2:S7-11.

16. Massukawa Oda DT, Ganança CF. Computerized dynamic posturography in the assessment of body balance in individuals with vestibular dysfunction. Audiol Commun Res. 2015;20(2):89-95. https://doi.org/10.1590/S231764312015000200001469

17. Croall ID, Tozer DJ, Moynihan B, Khan U, O'Brien JT, Morris RG, et al. Effect of standard vs. intensive blood pressure control on cerebral blood flow in small vessel disease. The PRESERVE Randomized Clinical Trial. JAMA Neurol. 2018;75(6):720-7. https://doi.org/10.1001/jamaneurol.2017.5153.

18. Yu X, Wang G, Zhan J, Zhang Z, Feng T, Xu J. Risk factors of pure leukoaraiosis and the association with preclinical carotid atherosclerosis. Atherosclerosis. 2018:275:328-32. https://doi.org/10.1016/j.atherosclerosis.2018.06.869.

19. Walsh El, Shaw M, Sachdev P, Anstey KJ, Cherbuin N. The impact of type 2 diabetes and body mass index on cerebral structure is modulated by brain reserve. Eur J Neurol. 2019;26(1):121-7. https://doi.org/10.1111/ene.13780. 
20. Madden DJ, Parks EL, Tallman CW, Boylan MA, Hoagey DA, Cocjin SB, et al. Sources of disconnection in neurocognitive aging: cerebral white-matter integrity, resting-state functional connectivity, and white-matter hyperintensity volume. Neurobiol Aging. 2017;54:199-213. https:/doi.org/ 10.1016/j.neurobiolaging.2017.01.027.

21. Abd Ghafar MZA, Miptah HN, O'Caoimh R. Cognitive screening instruments to identify vascular cognitive impairment: A systematic review. Int J Geriatr Psychiatry. 2019;34:1114-27. https://doi.org/10.1002/gps.5136.

22. Rensma SP, van Sloten $T$, Launer $\amalg$, Stehouwer CDA. Cerebral small vessel disease and risk of incident stroke, dementia and depression, and all-cause mortality: A systematic review and meta-analysis. Neurosci Biobehav Rev. 2018;90:164-73. https://doi.org/10.1016/j.neubiorev.2018.04.003.

23. Bahnasy WS, El-Heneedy YAE, Ragab OAA, Badr MY, Seleem MAH, Amer RA, et al. Polysomnography, brain volumetry, and mismatch negativity as early biomarkers of amnestic mild cognitive impairment progression. Egypt J Neurol Psychiatry Neurosurg. 2018;54:20. https:/doi.org/10.1186/s41983-018-0022-2.

24. Shen DC, Wu SL, Shi YZ, Wang S, Zhang YM, Wang CX. The correlation between white matter hyperintensity and balance disorder and fall risk: An observational, prospective cohort study. Chronic Dis Transl Med. 2016;2(3): 173-80. https://doi.org/10.1016/j.cdtm.2016.11.008.

25. Moscufo N, Wakefield DB, Meier DS, Cavallari M, Guttmann CRG, White WB, et al. Longitudinal microstructural changes of cerebral white matter and their association with mobility performance in older persons. PLoS One. 2018;13(3):e0194051. https://doi.org/10.1371/journal.pone.0194051.

26. Loos CMJ, Makin SDJ, Staals J, Dennis MS, van Oostenbrugge RJ, Wardlaw JM. Long-term morphological changes of symptomatic lacunar infarcts and surrounding white matter on structural magnetic resonance imaging. Stroke. 2018;49:1 183-8. https://doi.org/10.1161/STROKEAHA.117.020495.

27. Tuladhar AM, van Dijk E, Zwiers MP, van Norden AGW, de Laat KF, Shumskaya E, et al. Structural network connectivity and cognition in cerebral small vessel disease. Hum Brain Mapp. 2016;37:300-10. https://doi.org/10.1002/hbm.23032.

28. Frey BM, Petersen M, Mayer C, Schulz M, Cheng B, Thomalla G. Characterization of white matter hyperintensities in large-scale MRl-studies. Front Neurol. 2019. https://doi.org/10.3389/fneur.2019.00238.

29. Vangberg TR, Eikenes L, Håberg AK. The effect of white matter hyperintensities on regional brain volumes and white matter microstructure, a populationbased study in HUNT. Neurolmage. 2019;203:116158. https://doi.org/10.1016/s. neuroimage.2019.116158.

\section{Publisher's Note}

Springer Nature remains neutral with regard to jurisdictional claims in published maps and institutional affiliations.

\section{Submit your manuscript to a SpringerOpen ${ }^{\circ}$ journal and benefit from:}

- Convenient online submission

- Rigorous peer review

- Open access: articles freely available online

- High visibility within the field

- Retaining the copyright to your article

Submit your next manuscript at $\boldsymbol{\nabla}$ springeropen.com 